\title{
Molecular structure, spectroscopic (UV-vis, FT-IR and FT- Raman), conformational aspects of $3 t$-pentyl-2r,6c-di(naphthalen-1-yl) piperidin-4-one oxime: a comprehensive experimental and DFT study
}

\author{
K. Anandhy ${ }^{1,2}$, M. Arockia doss ${ }^{3}$, S. Amala ${ }^{3}$, G. Rajarajan ${ }^{3 *}$, S. Mahalakshmi ${ }^{1}$ \\ ${ }^{1}$ Post Graduate and Research, Department of Chemistry, Pachaiyappa's College,Chennai-600 030, India \\ ${ }^{2} P G$ Department of Chemistry, Periyar Govt. Arts College, Cuddalore-607001, India \\ ${ }^{3}$ Department of Chemistry, Annamalai University, Annamalainagar- 608 002, India \\ *Corresponding author E-mail:rajarajang70@gmail.com
}

\begin{abstract}
The molecular structure and conformational aspects of 3t-pentyl-2r,6c-di(naphthalen-1-yl)piperidin-4-one oxime (3-PDNPO) were studied by using B3LYP level with 6-31G(d,p) p basis set. The optimized geometrical parameters are in agreement with analogue available single XRD data. The optimized parameters showed that the piperidin-4-one ring adopts chair conformation.The FT- IR and FT-Raman spectra were recorded within the region $4000-400 \mathrm{~cm}^{-1}$ and $4000-10 \mathrm{~cm}^{-1}$, respectively. It was found by experimental wavenumbers and DFT wavenumbers were in good agreement. Electronic properties are investigated using TD-DFT/B3LYP method using 6-31G $(\mathrm{d}, \mathrm{p})$ basis set and compared with experimental UV-visible spectra. Additionally, the $\Delta \mathrm{E}$ gap investigated three phases follows the order of $\mathrm{CHCl} 3>$ gas > Methanol. The favourite sites for substitution reactions were evaluated by Mulliken and MEP analyses. From NLO analysis, it is found that the hyperpolarizability values are two times greater than the urea.Our proposed simulation procedure offers an alternative compound with which we can evaluate or design the best candidate NLO material.
\end{abstract}

Keywords:3-PDNPO; FT-IR; FT-Raman; HOMO-LUMO ;Hyperpolarizability.

\section{Introduction}

Piperidine-4-ones are heterocyclic compounds that have been the subject of extensive research for many years due to their applications in the field of biological activities such as antitumor, antibacterial, antiviral, antimalarial and antiprotozoal activities (Klayman et al. 1979; Gopalakrishnan et al. 2008; Bharti et al. 2002; Jayabharathi et al. 2011), optical fields (Jayabharathi et al. 2011; Jayabharathi et al. 2012), etc., Therefore, the biological importance of piperidine-4-one and its derivatives have strongly stimulated the investigation of computational properties available for these compounds. DFT calculations give accurate results on systems containing large organic molecules (Leeet al. 1988; Subashchandrabose et al. 2011; Arockia doss et al. 2015). As a continuation of our previous work (Anandhy et al. 2016), we focus herein on a new collection incorporation of oxime analogue at ketone functionality of piperidone ring and to extend the study to 3-pentyl-2,6-di(naphthalene-1-yl)piperidin-4-one oxime. The benefit of introducing oxime analogue into piperidine-4-one compounds is a consequence of the alteration of their physicochemical characteristics. The modified properties are characterizing them from the FT- IR and FT-Raman spectra and to study their quantum chemical descriptor in gas phase by means of a computational approach. In the present study, DFT/ 6-31G (d,p) level theory was used to determine the optimized geometry, vibrational wavenumbers in the ground state, non-linear optical properties, HOMO-LUMO energies and Mulliken charges of the molecules.

\section{Experimental}

2.1. Synthesis of $3 t$-pentyl-2r,6c-di(naphthalene-1yl)piperidin-4-one oxime

The compound 3-PDNPO was prepared according to the procedure given in literature with a little modification (Savithiri et al. 2014). 3-pentyl-2,6-di(naphthalene-1-yl)piperidin-4-one (0.05 mol) and sodium acetate trihydrate $(0.15 \mathrm{~mol})$ were dissolved in boiling ethanol and hydroxylamine hydrochloride $(0.06 \mathrm{~mol})$ was added. The mixture was kept warm at $40^{\circ} \mathrm{C}$, stirred for 3-4 hrs and then poured into crushed ice. The separated solid was filtered off and recrystallized from ethanol. Yield 80\%; m.p.: 192-195 $\left({ }^{\circ} \mathrm{C}\right)$; MF: $\mathrm{C}_{30} \mathrm{H}_{32} \mathrm{~N}_{2} \mathrm{O}$; Elemental analysis reported as follows : Calculated (\%): C, 82.53; H, 7.39; N, 6.42;O, 3.66; Experimental (\%): C, 82.03; H, 7.43; N, 6.24; IR (KBr) $\left(\mathrm{cm}^{-1}\right): 3391(\mathrm{O}-\mathrm{H}$ stretching), 3178(N-H stretching), 3062 (ArC-H stretching), 2927 Ali.C-H stretching), 1599 ( $\mathrm{C}=\mathrm{N}$ stretching), $1448 \quad(\mathrm{C}=\mathrm{C}$ stretching), $1015,977,953$ (Aromatic C-C in-plane bending vibration), $863,775,743$ (Aromatic C-H out-of-plane bending vibration).

\subsection{Spectral measurements}


Absorption spectral measurements were carried out with a Shimadzu (UV 1650 PC model) UV-visible spectrophotometer. The FT-IR spectrum of 3-PDNPO was taken in the range 4000-400 $\mathrm{cm}^{-1}$ on an AVATAR-330 FT-IR spectrometer (Thermo Nicolet) using $\mathrm{KBr}$ (pellet form). The FT-Raman spectral measurements were done, usingSophisticated Analytical Instrument Facility (SAIF), Indian Institute of Technology (IIT), Chennai.

\subsection{Theoretical background}

All calculations were carried out by Density Functional Theory (DFT) on a personal computer using Gaussian 03W program package (Frisch et al. 2004). The calculations were done with the B3LYP level and the basis set $6-31 \mathrm{G}(\mathrm{d}, \mathrm{p})$ was used in the present study to investigate the molecular and vibrational frequency of molecules in the ground state in order to support and explain the experimental observations. Mulliken, frontier molecular orbital and Non-linear optics (NLO) were calculated from optimized geometry of the molecule.

\section{Results and discussion}

\subsection{Conformational analysis}

In piperidone derivatives the most stable conformer is the chair form (Arockia doss et al. 2015; Manimekalai et al. 2012; Arockia doss et al. 2017). The oxime analogue has rotatable bonds, and so several conformers (Fig. 1) are possible for 3-PDNPO. These structures were subjected computations method using semiemprical/AM1.The ground state energy, energy difference and dipole moment of conformers are presented in Table 1.From the calculated energies the conformer 1 is found to be more stable.
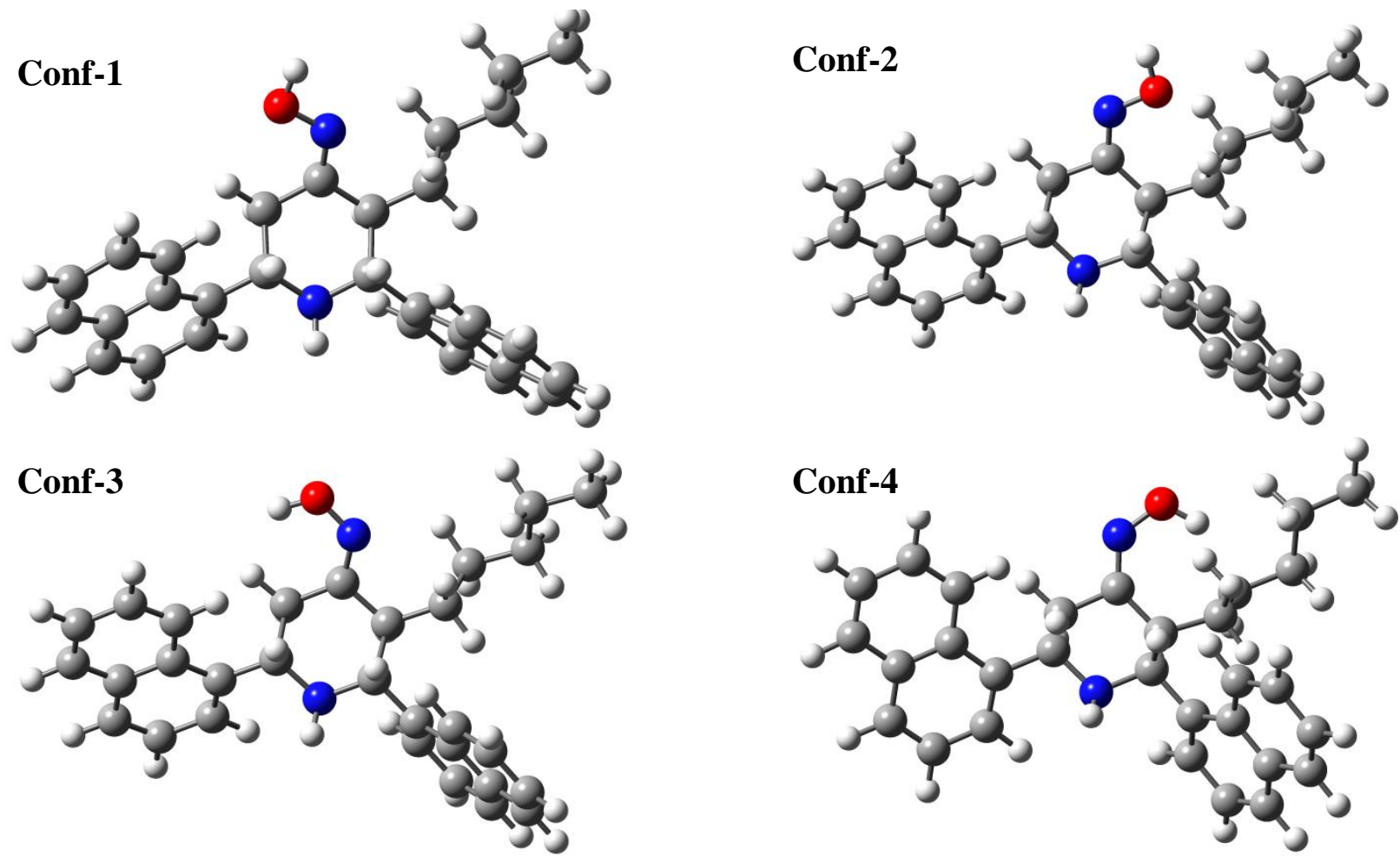

Fig. 1:Possible Conformers of 3-PDNPO.

Table 1: Calculated Energies and Energy Differences of Possible Conformers of the 3-PDNPO.

\begin{tabular}{|c|c|c|c|c|c|}
\hline & \multicolumn{2}{|l|}{ Energy } & \multicolumn{2}{|c|}{ Energy difference } & \multirow[t]{2}{*}{ Dipole moment } \\
\hline & Hartee & Kcal & Hartee & Kcal & \\
\hline Conf-1 & 0.103111 & 64.70328 & 0 & 0 & 0.78 \\
\hline Conf-2 & 0.105733 & 66.34869 & -0.00262 & -1.64541 & 0.71 \\
\hline Conf -3 & 0.109951 & 68.99545 & -0.00684 & -4.29217 & 2.97 \\
\hline Conf -4 & 0.107354 & 67.36572 & -0.00424 & -2.66244 & 2.81 \\
\hline
\end{tabular}

\subsection{Geometry optimization}

The optimized bond lengths, bond and dihedral angles of 3-PDNPO were calculated by B3LYP method with 6-31G (d,p) basis set level theory and the results are listed in Table 2, optimized structure with atom numbering scheme as shown in Fig. 2.

The optimized geometrical parameters are compared with the crystal structure of t-3-pentyl-r-2,c-6-diphenylpiperidin-4-one (Gayathri et al. 2008). The calculated $\mathrm{C}-\mathrm{C}$ bond distance in the piperidine ring is in the range $1.569-1.505 \AA$ by B3LYP/6$31 \mathrm{G}(\mathrm{d}, \mathrm{p})$ nearly coincides with experimental values (Gayathri et al. 2008). Literature value for $\mathrm{C}-\mathrm{H}$ bond distance is $1 \AA$. The computed bond length lies between 1.104-1.089 $\AA$ for heterocyclic ring. The $\mathrm{C} 2-\mathrm{C} 3-\mathrm{N} 63$ and $\mathrm{C} 4-\mathrm{C} 3-\mathrm{N} 63$ angles are found to be 118.40 and $125.84^{\circ}$. The hydroxyl group present in the oxime analogue influences the bond angle. It is known from previous studies (Arockia doss et al. 2015; Manimekalai et al. 2012; Arockia doss et al. 2017).The results from Table 2 showed that the piperidone ring essentially adopts chair conformation and also it is evident from the torsional angles N12-C5-C4-C3 (-54.81 and $-51.99^{\circ}$ at B3LYP and XRD, respectively), N12-C1-C2-C3 $\left[55.64^{\circ}\right.$ (B3LYP), $54.81^{\circ}$ (XRD)]. The equatorial orientation of alkyl and aryl groups are identified by their bond angles N12-C5C4-C47 [-177.82 (B3LYP) and -178.04 (XRD)] and C47-C4-C3$\mathrm{C} 2$ [179.01 (B3LYP) and $177.45^{\circ}$ (XRD)]. The results from Table 2 show that $\mathrm{O}-\mathrm{H}$ group anti to pentyl group and are the stable conformer. It is supported by available crystal data (Jayabharathi et al. 2008). 


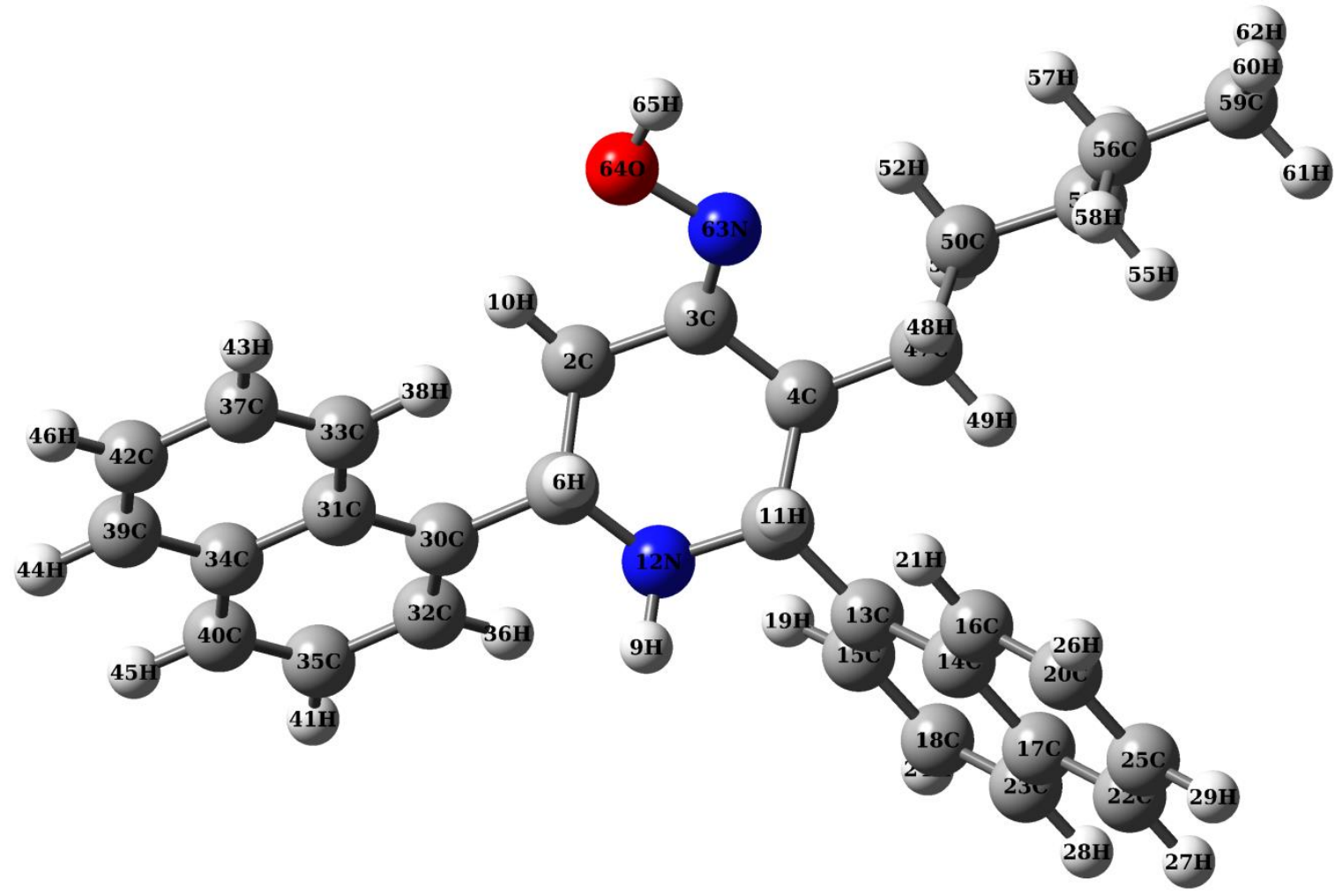

Fig. 2: Optimized Structure and Numbering Scheme of 3-PDNPO.

Table 2: Selected Bond Lengths, Bond Angles and Dihedral Angles of 3-PDNPO

\begin{tabular}{|c|c|c|c|c|c|}
\hline Bond length $(\AA)$ & DFT & XRD & Bond angle $\left({ }^{\circ}\right)$ & DFT & XRD \\
\hline $\mathrm{C} 5-\mathrm{N} 12$ & 1.475 & 1.471 & C4-C5-H11 & 106.30 & 109 \\
\hline $\mathrm{C} 5-\mathrm{C} 4$ & 1.569 & 1.549 & C4-C5-N12 & 108.84 & 109.32 \\
\hline C5-H11 & 1.101 & 1 & C4-C5-C13 & 112.99 & 112.3 \\
\hline C4-H8 & 1.100 & 1 & $\mathrm{C} 5-\mathrm{C} 13-\mathrm{C} 15$ & 118.19 & 120.94 \\
\hline C4-C3 & 1.519 & 1.526 & C5-C13-C14 & 122.68 & 120.46 \\
\hline $\mathrm{C} 4-\mathrm{C} 47$ & 1.537 & 1.531 & C2-C1-N12 & 107.75 & 107.47 \\
\hline $\mathrm{C} 3-\mathrm{C} 2$ & 1.505 & 1.506 & $\mathrm{C} 2-\mathrm{C} 1-\mathrm{C} 30$ & 111.66 & 110.8 \\
\hline C3-N63 & 1.282 & 1.211 & C2-C1-H6 & 107.04 & 109 \\
\hline N63-O64 & 1.415 & & C3-N63-O64 & 112.55 & \\
\hline O64-H65 & 0.966 & - & C4-C3-N63 & 125.84 & - \\
\hline C2-H10 & 1.089 & 1 & C2-C3-N63 & 118.40 & - \\
\hline C2-H7 & 1.096 & 1 & N12-C1-C30 & 111.42 & 110.6 \\
\hline $\mathrm{C} 2-\mathrm{C} 1$ & 1.550 & 1.532 & C1-C30-C32 & 120.15 & 119.91 \\
\hline C1-H6 & 1.104 & 1 & $\mathrm{C} 1-\mathrm{C} 30-\mathrm{C} 31$ & 120.59 & 121.16 \\
\hline C1-N12 & 1.467 & 1.466 & Dihedral $\left({ }^{\circ}\right)$ & & \\
\hline $\mathrm{C} 1-\mathrm{C} 30$ & 1.522 & 1.513 & N12-C5-C4-C47 & -177.82 & -178.04 \\
\hline $\mathrm{C} 13-\mathrm{C} 15$ & 1.384 & 1.395 & $\mathrm{C} 47-\mathrm{C} 4-\mathrm{C} 3-\mathrm{C} 2$ & 178.19 & 171.84 \\
\hline C14-C17 & 1.439 & 1.386 & C47-C4-C3-N63 & -7.43 & -7.74 \\
\hline $\mathrm{C} 15-\mathrm{C} 18$ & 1.412 & 1.3922 & $\mathrm{~N} 12-\mathrm{C} 5-\mathrm{C} 4-\mathrm{C} 3$ & -54.81 & -51.99 \\
\hline $\mathrm{C} 17-\mathrm{C} 23$ & 1.419 & 1.3782 & N12-C1-C2-C3 & 55.64 & 54.81 \\
\hline \multirow[t]{2}{*}{$\mathrm{C} 18-\mathrm{C} 23$} & 1.374 & 1.387 & C47-C4-C5-C13 & -57.14 & 61.21 \\
\hline & & & $\mathrm{C} 47-\mathrm{C} 4-\mathrm{C} 3-\mathrm{C} 2$ & 179.01 & 177.45 \\
\hline
\end{tabular}

\subsection{Vibrational analyses}

The vibrational assignment and analysis of the fundamental modes of the 3-PDNPO molecule were carried out using the observed FT-IR and FT-Raman data, which are shown in Fig. 3. The harmonic vibrational wavenumbers were calculated by means of the DFT-B3LYP/6-31 G(d,p) method at the corresponding optimized structure. DFT hybrid B3LYP functional methods tend to overestimate the fundamental modes. Therefore, a scale factor has been used for obtaining a considerable result which is in better agreement with the experimental data. Thus, the scale factor 0.9608 (Arockia doss et al. 2015) has been uniformly applied to the DFT/ B3LYP method. The observed positions of vibrational bands and their assignments are summarizedinTable 3 for
3-PDNPO. Fig. 3, shows the absence of $\mathrm{C}=\mathrm{O}$ band (Socrates 1980) in the spectrum of the oxime and presence of new bands at 3391 and $1599 \mathrm{~cm}^{-1}$ which are due to the $\mathrm{O}-\mathrm{H}$ and $\mathrm{C}=\mathrm{N}$ of title compound.

The N-H (Pavia et al. 2008) stretching frequency observed at $3178 \mathrm{~cm}^{-1}$, which is supported by computed value at $3377 \mathrm{~cm}^{-1}$. In spite of the good agreement between the experimental and calculated data, as expected the theoretical wave numbers are slightly over estimated, this may be mainly due to the omission of anharmonicity.

In aromatic structures, the characteristic $\mathrm{C}-\mathrm{H}$ stretching vibrations are expected to appear in the range of $3010-3080 \mathrm{~cm}^{-1}$ (Socrates 1980). Aromatic C-H stretching vibrations are expressed in a strong band at 3062 and $3049 \mathrm{~cm}^{-1}$ in FT-IR and Raman spectra, respectively. The corresponding computed value matches with 
$3085 \mathrm{~cm}^{-1}$. The methyl group (Silverstein et al. 2005) C-H stretching is observed at $2927 \mathrm{~cm}^{-1}$ for 3-PDNPO. On the basis of computations, the scaled wavenumber at $2982 \mathrm{~cm}^{-1}$ matched with experimental value. In the present study, the wavenumbers observed in the FT-IR and Raman spectra at 1448 and $1444 \mathrm{~cm}^{-1}$, respectively are assigned to $\mathrm{C}=\mathrm{C}$ stretching vibration. The IR absorption at $1037 \mathrm{~cm}^{-1}$ is ascribed to C-N stretching mode, whereas Raman band near $1035 \mathrm{~cm}^{-1}$ is attributed to vibration the above mentioned. The $\mathrm{C}-\mathrm{H}$ in-plane bending modes are identified near 1015, 977 and $953 \mathrm{~cm}^{-1}$ in FT-IR and 1016, $1007 \mathrm{~cm}^{-1}$ in Raman spectrum. Their computational vibrational modes appeared in range from 1040-959 $\mathrm{cm}^{-1}$. The bands in the range $863-743 \mathrm{~cm}^{-1}$ (FT-IR) and $886 \& 767$ (Raman) are responsible for C-H out of plane bending modes. According to the computations, the bands observed in the region $884-749 \mathrm{~cm}^{-1}$.

Table 3: Observed and Calculated Wavenumbers $\left(\mathrm{cm}^{-1}\right)$ and Their Vibrational Assignments of 3-PDNPO

\begin{tabular}{|c|c|c|c|c|c|c|}
\hline $\begin{array}{l}\text { Experimental } \\
\text { FT-IR }\end{array}$ & FT-Raman & \multicolumn{2}{|l|}{ Frequencies } & IR intensity & Raman activity & $\begin{array}{l}\text { Vibrational } \\
\text { Assignments }\end{array}$ \\
\hline 743 & & 780 & 749 & 8.21 & 5.63 & \\
\hline 775 & 767 & 816 & 784 & 53.75 & 0.89 & $\Gamma_{\mathrm{C}-\mathrm{H}}$ \\
\hline 863 & 886 & 920 & 884 & 2.35 & 10.27 & \\
\hline 953 & & 998 & 959 & 58.82 & 1.33 & \\
\hline 977 & 1007 & 1034 & 993 & 8.73 & 5.47 & $\beta_{\mathrm{C}-\mathrm{H}}$ \\
\hline 1015 & 1016 & 1082 & 1040 & 1.72 & 21.67 & \\
\hline 1037 & 1035 & 1104 & 1061 & 10.72 & 21.67 & $v_{\mathrm{C}-\mathrm{N}}$ \\
\hline 1170 & 1173 & 1242 & 1193 & 6.00 & 1.07 & $v_{\mathrm{C}-\mathrm{O}}$ \\
\hline 1448 & 1444 & 1513 & 1454 & 4.90 & 17.91 & $v_{\mathrm{C}=\mathrm{C}}$ \\
\hline 1599 & 1575 & 1710 & 1643 & 8.47 & 26.94 & $v_{\mathrm{C}=\mathrm{N}}$ \\
\hline 2927 & & 3104 & 2982 & 75.45 & 30.62 & $v_{\mathrm{C}-\mathrm{H}}$ \\
\hline 3062 & 3049 & 3211 & 3085 & 7.65 & 136.16 & $v_{\text {ArC-H }}$ \\
\hline 3178 & & 3515 & 3377 & 0.05 & 82.60 & $v_{\mathrm{N}-\mathrm{H}}$ \\
\hline 3391 & & 3822 & 3672 & 71.51 & 171.56 & $v_{\mathrm{O}-\mathrm{H}}$ \\
\hline scale fa & ictor:0.9608- & YP/6-31G(d, & & & & \\
\hline$v:$ stretc & ching; $\beta$-in-p & ending: $\Gamma-\mathrm{ol}$ & ne bendin & & & \\
\hline
\end{tabular}
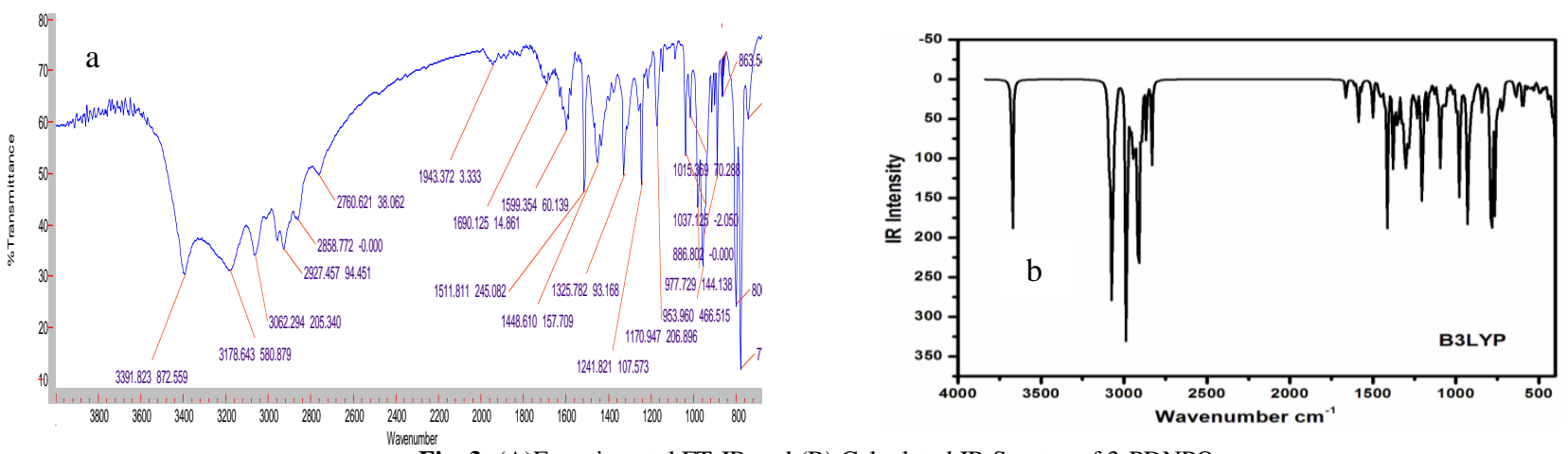

Fig. 3: (A)Experimental FT-IR and (B) Calculated IR Spectra of 3-PDNPO
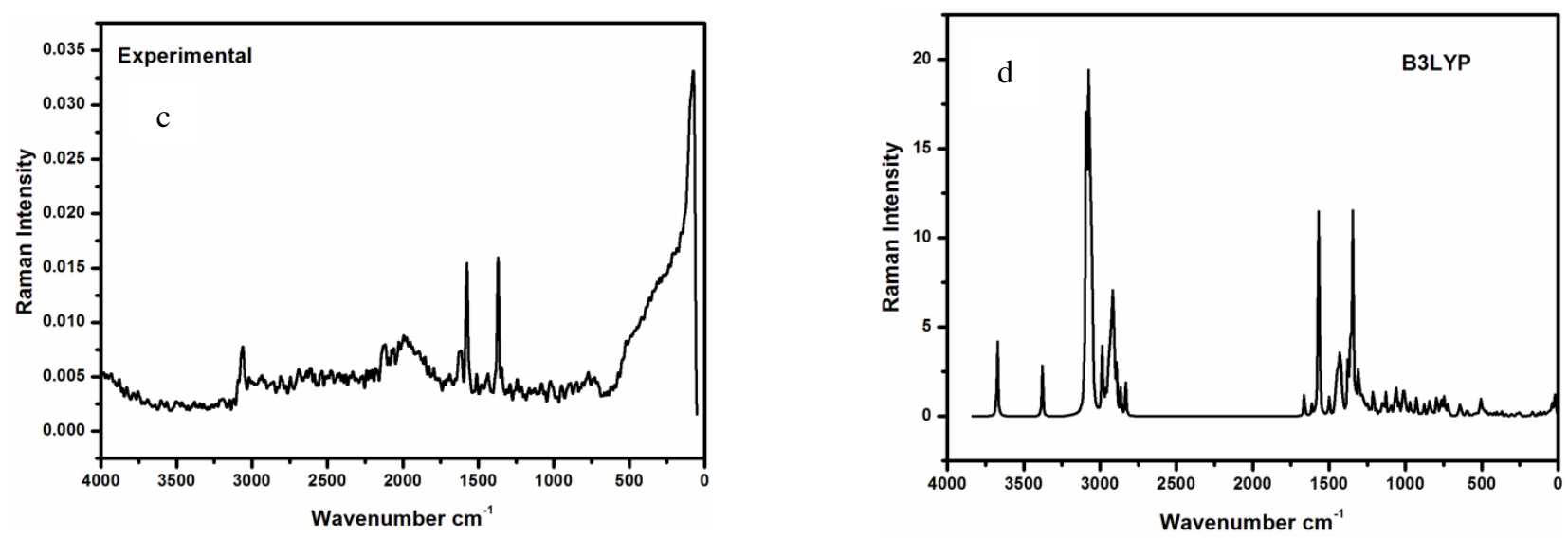

Figs 3: (C) Experimental FT-Raman and 3 (D) Calculated Raman Spectra of 3-PDNPO

\subsection{Natural bond orbital analysis}

NBO analysis offers useful insights into the intramolecular delocalization and donor- acceptor interactions based on the second order interactions between filled and vacant orbitals. It is better to understand the importance of ground state stabilization interactions that make the molecules to be stable in the ground state (Szafran et al. 2007; James et al. 2006; Arockia doss et al. 2016). Hence, NBO analysis has been carried out and the results are summarized in Table 4. This table lists the major second order perturbation interactions along with the corresponding donor and acceptor NBOs.
The second-order perturbation theory analysis of Fock-matrix in NBO basis showed that the strong intermolecular hyper conjugative interactions are formed by orbital overlap between $\pi(\mathrm{C}-\mathrm{C}) \rightarrow$ $\pi^{*}(\mathrm{C}-\mathrm{C}), \pi(\mathrm{C}-\mathrm{C}) \rightarrow \sigma *(\mathrm{C}-\mathrm{C})$, orbital which result in intramolecular charge transfer causing stabilization of the system.

There occurs an inter molecular hyper conjugative interaction of C14-C17 from C13-C15, which increases ED (0.47) that weakens the respective bonds $\mathrm{C} 13-\mathrm{C} 1$ leading to stabilization of $66.15 \mathrm{KJ} / \mathrm{mol}$. It is interesting to note that in the molecule, the lone pair on $\mathrm{N}, \mathrm{O}$ atoms participate in the stabilization of 3-PDNPO through $n-\sigma^{*}$ and $n-\pi^{*}$ interactions contributing 42.93-60.42 $\mathrm{kJ} / \mathrm{mol}$ towards stabilization. Yet the predominant stabilizing in- 
teractions in 3-PDNPO is $n-\pi^{*}$ interactions arising from lone pair of oxygen to the $\pi^{*}$ of adjacent $\mathrm{C}-\mathrm{N}$ bond which is more dominant than the $n-\sigma^{*}$. Overall the results highlight the importance of the oxime unit towards the ground state stabilization of molecules.In addition, the nitrogen atom in oxime group also takes part in the stabilization through $\mathrm{n}-\sigma^{*}$ interactions.

\subsection{Mulliken charge analysis}

The Mulliken atomic charges are calculated by determining the electron population of each atom as defined by the basis function. The Mulliken atomic charges of 3-PDNPO molecule calculated by
B3LYP using 6-31G (d,p) basis set and are listed in Table 5 and Fig. 4. Mulliken atomic charge calculation plays a vital role for the application of quantum chemical calculation of the molecular system. In 3-PDNPO, the maximum positive charge (0.2840) for $\mathrm{C} 3$ atom than other atoms is due to the presence of largely electronegative nitrogen (N63) oxygen (O64) atoms in the closest position. The nitrogens N63 (-0.25971), N12 (-0.3040) and oxygen O64 (-0.10150) atoms have more negative charge than the other atoms. Hence, carbon (C3), hydrogen (H8) and oxygen (O13) may be the possible reactive sites of 3-PDNPO.

Table 4: Second Order Perturbation theory analysis of Fock Matrix in NBO basis

\begin{tabular}{|c|c|c|c|c|c|c|c|}
\hline Type & Donor (i) & $\mathrm{ED} / \mathrm{e}$ & Acceptor (j) & $\mathrm{ED} / \mathrm{e}$ & $\mathrm{E}^{(2)}(\mathrm{KJ} / \mathrm{mol})$ & $E(j)-E(i)(a . u)$ & $F(i, j)(a . u)$ \\
\hline$\sigma-\pi^{*}$ & C1-C2 & 1.95365 & C3-N63 & 0.14 & 13.93 & 0.62 & 0.041 \\
\hline$\sigma-\sigma^{*}$ & & & H9-N12 & 0.01 & 9.25 & 1.05 & 0.043 \\
\hline$\sigma-\sigma^{*}$ & C1-H6 & 1.97482 & C2-H7 & 0.01 & 10.17 & 0.95 & 0.043 \\
\hline$\sigma-\sigma^{*}$ & & & C30-C32 & 0.26 & 11.92 & 1.11 & 0.05 \\
\hline$\sigma-\sigma^{*}$ & C4-C47 & 1.97734 & C2-C3 & 0.04 & 10.21 & 1.01 & 0.044 \\
\hline$\sigma-\sigma^{*}$ & C5-H11 & 1.97837 & C13-C15 & 0.02 & 14.23 & 1.1 & 0.055 \\
\hline$\sigma-\sigma^{*}$ & C5-N12 & 1.98074 & C1-C30 & 0.03 & 7.61 & 1.12 & 0.04 \\
\hline$\sigma-\sigma^{*}$ & C13-C14 & 1.97181 & C13-C15 & 0.02 & 14.23 & 1.27 & 0.059 \\
\hline$\pi-\pi *$ & C13-C15 & 1.7267 & C14-C17 & 0.47 & 66.15 & 0.28 & 0.063 \\
\hline$\pi-\pi *$ & & & C18-C23 & 0.26 & 74.10 & 0.29 & 0.064 \\
\hline$\sigma-\sigma^{*}$ & C14-C17 & 1.53196 & C5-C13 & 0.03 & 13.93 & 1.08 & 0.054 \\
\hline$\pi-\pi *$ & & & C13-C15 & 0.27 & 69.58 & 0.28 & 0.064 \\
\hline$\pi-\pi *$ & & & C16-C20 & 0.26 & 70.12 & 0.27 & 0.064 \\
\hline$\pi-\pi *$ & C16-C20 & 1.74458 & C14-C17 & 0.47 & 65.86 & 0.29 & 0.063 \\
\hline$\pi-\pi *$ & & & C22-C25 & 0.25 & 72.17 & 0.29 & 0.064 \\
\hline$\pi-\pi *$ & C18-C23 & 1.73765 & C13-C15 & 0.25 & 74.52 & 0.3 & 0.065 \\
\hline$\pi-\pi *$ & & & C14-C17 & 0.21 & 69.16 & 0.29 & 0.065 \\
\hline$\pi-\pi *$ & C22-C25 & 1.98134 & C14-C17 & 0.47 & 68.03 & 0.29 & 0.064 \\
\hline$\pi-\pi *$ & & & C16-C20 & 0.25 & 74.60 & 0.29 & 0.065 \\
\hline$\pi-\pi *$ & C30-C32 & 1.73405 & C35-C40 & 0.26 & 73.81 & 0.29 & 0.064 \\
\hline$\pi-\pi *$ & C31-C34 & 1.5369 & C $30-\mathrm{C} 32$ & 0.26 & 69.58 & 0.28 & 0.064 \\
\hline$\pi-\pi *$ & & & C33-C37 & 0.26 & 70.79 & 0.27 & 0.064 \\
\hline$\pi-\pi *$ & C33-C37 & 1.74147 & C31-C34 & 0.46 & 66.36 & 0.29 & 0.064 \\
\hline$\pi-\pi *$ & & & C39-C42 & 0.26 & 72.55 & 0.29 & 0.064 \\
\hline$\pi-\pi *$ & C35-C40 & 1.74521 & C30-C32 & 0.26 & 72.17 & 0.3 & 0.064 \\
\hline$\pi-\pi *$ & & & C31-C34 & 0.26 & 68.41 & 0.29 & 0.065 \\
\hline$\pi-\pi *$ & C39-C42 & 1.74011 & C31-C34 & 0.26 & 68.32 & 0.29 & 0.065 \\
\hline$\pi-\pi *$ & & & C33-C37 & 0.26 & 74.89 & 0.29 & 0.065 \\
\hline$n-\sigma *$ & LP(1)N63 & 1.95546 & C2-C3 & 0.04 & 42.93 & 0.85 & 0.083 \\
\hline$n-\pi *$ & LP(2)O64 & 1.91775 & C3-N63 & 0.14 & 60.42 & 0.068 & 0.068 \\
\hline
\end{tabular}

Table 5: Mulliken charges of 3-PDNPO

\begin{tabular}{|c|c|c|c|}
\hline \\
\hline Atom & Charge & Atom & Charge \\
\hline $\mathrm{C} 1$ & 0.1177 & C30 & 0.03392 \\
\hline $\mathrm{C} 2$ & 0.0645 & $\mathrm{C} 31$ & 0.07169 \\
\hline $\mathrm{C} 3$ & 0.2840 & C32 & -0.03515 \\
\hline $\mathrm{C} 24$ & 0.0225 & $\mathrm{C} 33$ & -0.03922 \\
\hline C5 & 0.1042 & C34 & 0.09984 \\
\hline N12 & -0.3040 & $\mathrm{C} 35$ & -0.00819 \\
\hline $\mathrm{C} 13$ & 0.0246 & C37 & -0.01175 \\
\hline $\mathrm{C} 14$ & 0.0657 & C39 & -0.04895 \\
\hline C15 & -0.0190 & $\mathrm{C} 40$ & -0.04346 \\
\hline C16 & -0.0401 & $\mathrm{C} 42$ & -0.00273 \\
\hline C17 & 0.1014 & C47 & 0.03344 \\
\hline $\mathrm{C} 18$ & -0.0057 & C50 & 0.00429 \\
\hline $\mathrm{C} 20$ & -0.0099 & C53 & -0.00174 \\
\hline $\mathrm{C} 22$ & -0.0482 & C56 & 0.01784 \\
\hline $\mathrm{C} 23$ & -0.0436 & C59 & -0.02078 \\
\hline $\mathrm{C} 25$ & -0.0019 & N63 & -0.25971 \\
\hline & & O64 & -0.10150 \\
\hline
\end{tabular}




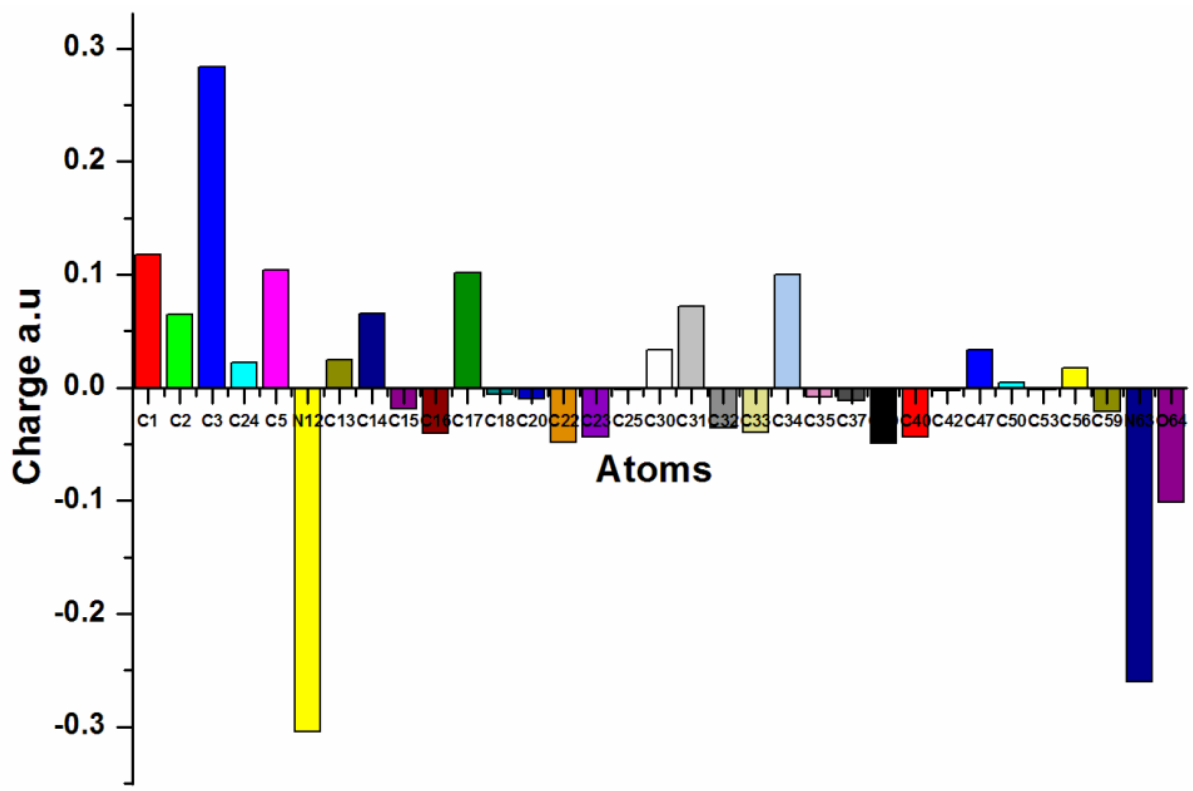

Fig. 4: Mulliken Plot of 3-PDNPO.

\subsection{Molecular electrostatic potential (MEP) analysis}

Molecular electrostatic potential is an eminent technique to demonstrate the structure and activity relationship (Okulik 2005). The possible regions for the electrophilic and nucleophilic invasion of molecular systems are evaluated from the MEP surfaces. The red colour region signify negative potential and blue colour for positive potential. Theelectrostatic potential is approximately zero for the green regions.

From Fig. 5, it is evident that the observed molecule has a number of potential sites for electrophilic and nucleophilic attack. As seen in Fig. 5, negative regions, where come into existence electrophilic attack, are oxygen atoms in $\mathrm{C}=\mathrm{N}$ moiety. Conversely, the regions having positive potential where as nucleophilic attack to molecule happens are H64. From the above results the noncovalent interactions taking place within the molecule are determined.

\subsection{UV-visible spectral analysis}

Further investigation of molecular level and understanding the relationship between the optical and the electronic properties of our compound were done using UV-visible spectra. The electronic spectra of the 3-PDNPO compound in chloroform and methanol solvents were recorded and shown in Fig. 6. There is no absorption band around 350 and $1000 \mathrm{~nm}$. The absence of absorption in the visible region in the 3-PDNPO compound makes them suitable chemical for NLO property (Vijayan et al. 2002; Savithiri et al. 2015). As seen from Fig. 6, electronic absorption spectra showed two bands at 307 and $255 \mathrm{~nm}$ for chloroform at 319 and $246 \mathrm{~nm}$ for methanol. Electronic absorption spectra were calculated using the TD-DFT method based on the B3LYP/6-31G (d,p) level optimized structure in gas and solvent phase. The calculated results are listed in Table 6 alongwith the experimental absorption spectral data. For TD-DFT calculations, the theoretical absorption bands are predicted at $342.18,290.56$ and $264.42 \mathrm{~nm}$ in gas phase, at $314.28,291.29$ and $268.85 \mathrm{~nm}$ in chloroform and 325.87 , 292.00 and $250.90 \mathrm{~nm}$ in methanol. The bands around $300 \mathrm{~nm}$ are assigned to $\mathrm{n}-\pi^{*}$ transition. The bands around $250 \mathrm{~nm}$ are assigned to $\pi-\pi *$ transition. The solvent in which the absorbing species is dissolved also has an effect on the spectrum of the species. Peaks resulting from $n-\pi^{*}$ transitions are shifted to longer wavelengths (red shift) with increasing solvent polarity. This emerges from increased solvation of the lone pair, which brings the energy from the $n$ orbital.

This is brought about by attractive polarisation forces between the solvent andabsorber, which increase the energy levels of both the excited and unexcited states.

The main contributions of the transitions were designated with the help of SWizard program (Gorelsky et al. 2010). In methanol phase, the maximum absorption wavelength corresponds to the electronic transition from the HOMO-LUMO with $86 \%$ contribution, the transition on HOMO-1-LUMOwith $85 \%$ and the transition HOMO-LUMO + 1 with $88 \%$.

DFT calculations commonly expose a HOMO with electron density localised on the donor unit and a LUMO with electron density localized on the acceptor unit. These orbital's take part in an imperative function in the electronic properties, optical properties and also determines the way the molecule interacts with other species (Mulliken 1995; Fleming 1976). The energy of the HOMO is representative of ionization potential while LUMO energy is indicating the electron affinity. The stability of structures has been explained by energy gap between HOMO and LUMO and this gap helps to characterize some significant issues including the kinetic stability besides chemical reactivity of the molecule (Curtiss et al. 1998). The compound with a tiny Frontier orbital space is more accountable for low kinetic stability and high chemical reactivity. The molecular electrical transport properties (Fukui et al. 1982; Udhayakala et al. 2011; Subramanian et al.. 2010) were determined by one of the critical parameters of energy gap between HOMO and LUMO.

The HOMO energy, the LUMO energy and the energy gap of 3 PDNPO is listed in Table 6. Fig. 7 depicts the molecular orbitals and energies for the HOMO-LUMO, where positive phase and negative phase of orbitals are represented in red and green colour. 

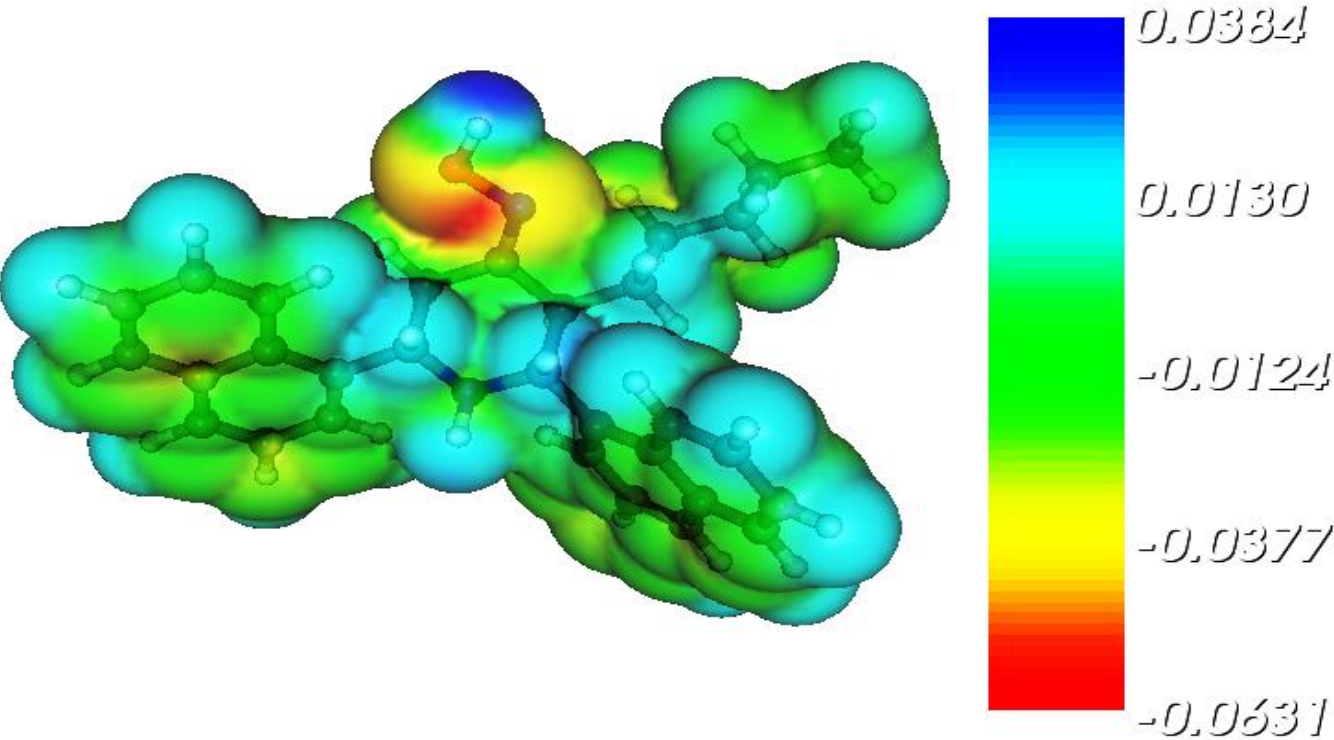

Fig. 5:MEP surface diagram of 3-PDNPO.
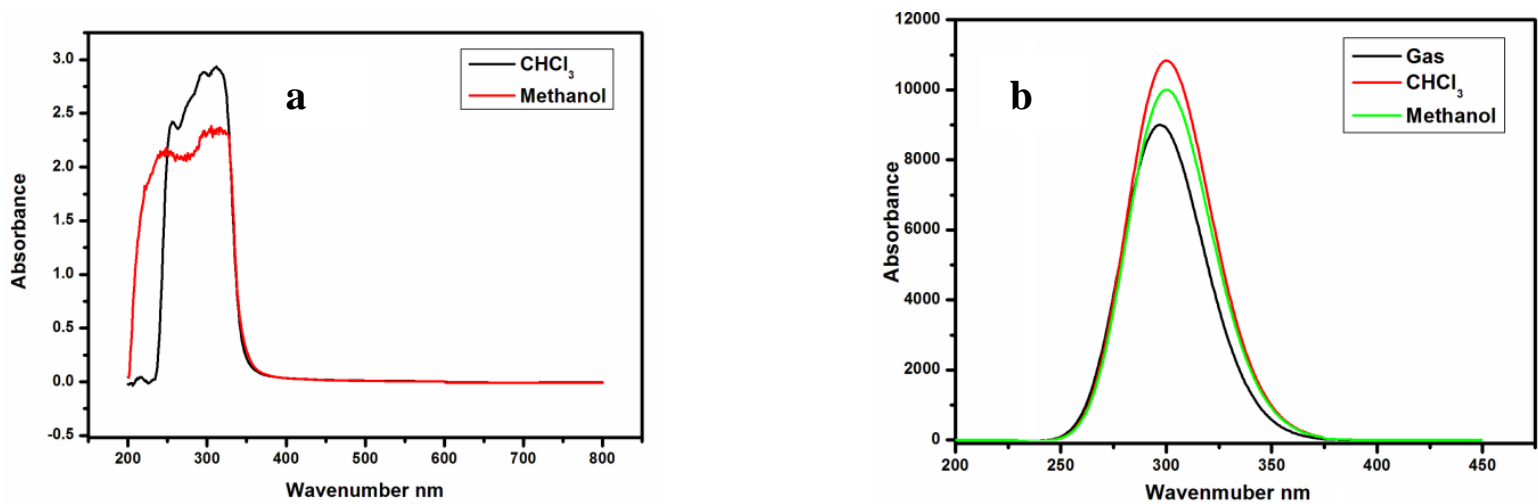

Fig. 6: (A) Experimental (B) Computed UV-visible Spectra of3-PDNPO.

Table 6: Computed and Experimental Absorption Maxima $\left(\lambda_{\max }, \mathrm{nm}\right)$, Oscillator Strength $(f)$ and Electronic Excitation Energies (E, eV) of 3-PDNPO.

\begin{tabular}{|c|c|c|c|c|c|}
\hline State & Cal. $\lambda_{\max }(\mathrm{nm})$ & Expt. $\lambda_{\max }(\mathrm{nm})$ & $\begin{array}{l}\text { Osicillator } \\
\text { Strength }(f)\end{array}$ & $\mathrm{E}(\mathrm{eV})$ & Main contributing configurations \\
\hline \multirow{3}{*}{ Gas phase } & 342.18 & & 0.107 & 3.62 & \multirow{8}{*}{$\begin{array}{l}\mathrm{H} \rightarrow \mathrm{L}(82 \%) \\
\mathrm{H} \rightarrow \mathrm{L}+2(24 \%) \\
\mathrm{H}-1 \rightarrow \mathrm{L}(76 \%) \\
\mathrm{H}-3 \rightarrow \mathrm{L}+1(90 \%) \\
\mathrm{H} \rightarrow \mathrm{L}(86 \%) \\
\mathrm{H} \rightarrow \mathrm{L}+2(16 \%) \\
\mathrm{H}-1 \rightarrow \mathrm{L}(85 \%) \\
\mathrm{H} \rightarrow \mathrm{L}+1(88 \%) \\
\mathrm{H} \rightarrow \mathrm{L}(85 \%) \\
\mathrm{H} \rightarrow \mathrm{L}+2(14 \%) \\
\mathrm{H}-1 \rightarrow \mathrm{L}(90 \%) \\
\mathrm{H}-3 \rightarrow \mathrm{L}+1(84 \%)\end{array}$} \\
\hline & 290.56 & & 0.0411 & 4.26 & \\
\hline & 265.42 & & 0.0767 & 4.67 & \\
\hline \multirow{2}{*}{ Methanol } & 325.87 & 319 & 0.0486 & 3.81 & \\
\hline & 292.00 & & 0.1247 & 4.24 & \\
\hline \multirow{3}{*}{ Chloroform } & 314.28 & 307 & 0.0864 & 3.95 & \\
\hline & 291.29 & & 0.1652 & 4.25 & \\
\hline & 268.85 & 255 & 0.0176 & 4.61 & \\
\hline
\end{tabular}

\subsection{Frontier molecular orbital analysis}

The calculated energy values of HOMO are $-5.73,-5.70$, and -5.70 $\mathrm{eV}$ in gas, methanol and chloroform, respectively. LUMO is -1.10 -1.06 , and $-1.05 \mathrm{eV}$ in gas, methanol and chloroform, respectively. The value of the energy separation between HOMO and LUMO is 4.63, 4.64 and $4.65 \mathrm{eV}$ in gas, methanol and chloroform, respectively. The energy gap of HOMO-LUMO explains the eventual charge transfer interaction taking place within the molecule, which influences the biological activity of the molecule. Furthermore, in going from the solution to the gas phase, an increasing value of the energy gap shows that the molecule becomes more stable.

The absolute electronegativity $(\chi)$, hardness $(\eta)$, electrophilicity index $(\psi)$ and softness $(\zeta)$ are calculated using the following equations $\eta=($ IP-EA $) / 2 \approx($ ELumo-Еномо $) / 2$

$\chi=(\mathrm{IP}+\mathrm{EA}) / 2 \approx-($ ELUMO + Еномо $) / 2$ $\psi=\mu^{2} / 2 \eta$

$\zeta=1 / 2 \eta$

For 3-PDNPO, electronegativity $(\chi)$, hardness $(\eta)$, electrophilicity index $(\psi)$ and softness $(\zeta)$ are given in Table 7 . The dipole moment is another important electronic property in a molecule. For example higher the dipole moment, the stronger will be the intermolecular interactions.

\subsection{Non-linear optical analysis}

Density functional theory has been used as an effective method to investigate the organic non-linear optical materials. Recent research works have illustrated that the organic non-linear optical materials are having high optical non-linearity than inorganic materials (Sun et al. 2003). In the presence of an applied electric field, the energy of a system is a function of the electric field. 
polarizabilities and hyperpolarizabilities characterize the response of a system in an applied electric field (Christiansen et al. 1999). They determine not only the strength of molecular interactions but also the cross sections of different scattering and collision processes, as well as the NLO properties of the system (Klein- man1977; Labidia et al. 2010; Vijayakumar et al. 2008). In this study the electronic dipole moment, molecular polarizability, anisotropy of polarizability and molecular first hyperpolarizability of present compound were investigated.
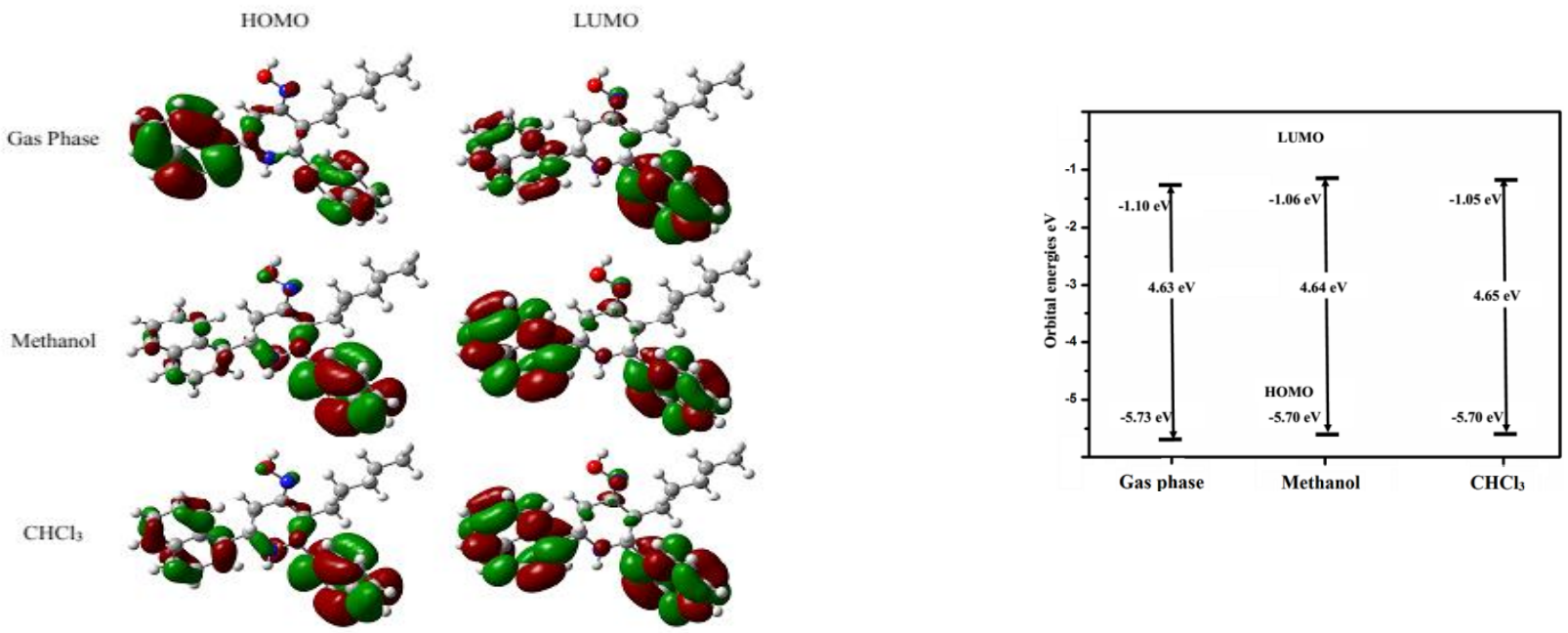

Fig. 7:Molecular orbitals and energies for 3-PDNPO

Table 7: Calculated energy values (eV) of 3-PDNPO in Gas Phase, Ethanol and Chloroform

\begin{tabular}{|c|c|c|c|}
\hline B3LYP/6-31G(d,p) & Gas & Methanol & $\mathrm{CHCl}_{3}$ \\
\hline Etotal (Hartree) & -1347.21 & -1347.24 & -1347.23 \\
\hline $\mathrm{E}_{\text {Номо }}$ & -5.73 & -5.70 & -5.70 \\
\hline $\mathrm{E}_{\text {LUOMO }}$ & -1.10 & -1.06 & -1.05 \\
\hline $\mathrm{E}_{\text {LUMO-номо }}(\Delta \mathrm{E})$ & 4.63 & 4.64 & 4.65 \\
\hline $\mathrm{E}_{\mathrm{HOMO}-1}$ & -5.78 & -5.76 & -5.75 \\
\hline $\mathrm{E}_{\mathrm{LUMO}+1}$ & -1.01 & -1.00 & -0.99 \\
\hline $\mathrm{E}_{\text {(HOMO-1)-(LUMO+1) }}$ & 4.77 & 4.76 & 4.75 \\
\hline Electrinegativity $(\chi)$ & -3.42 & -3.38 & -3.38 \\
\hline Electrophilicity index $(\psi)$ & 2.52 & 2.47 & 2.46 \\
\hline $\operatorname{Softness}(\zeta))$ & 159.72 & 159.63 & 159.23 \\
\hline Dipole moment & 0.92 & 1.33 & 1.18 \\
\hline
\end{tabular}

Table 8: Dipole Moment, Polarizabiltiy, Hperpolarizabiltyof 3-PDNPO Calculated Using B3LYP Method Using 6-31G (D,P) Basis Set.

\begin{tabular}{llll}
\multicolumn{1}{c}{ Table 8: Dipole Moment, Polarizabiltiy, Hperpolarizabiltyof 3-PDNPO Calculated Using B3LYP Method Using 6-31G (D,P) Basis Set. } & Hyperpolarizability (a.u) \\
\hline$\mu_{\mathrm{x}}$ & Dipolemoment (Debye) & Parameter & -89.1566 \\
$\mu_{\mathrm{y}}$ & -0.1127 & $\beta_{\mathrm{xxx}}$ & 50.5974 \\
$\mu_{\mathrm{z}}$ & -0.6139 & $\beta_{\mathrm{yyy}}$ & 7.1043 \\
$\mu_{\text {total }}$ & 0.6794 & $\beta_{\mathrm{zzz}}$ & 18.7385 \\
Parameter & 0.92 & $\beta_{\mathrm{xyy}}$ & -43.9223 \\
$\alpha_{\mathrm{xx}}$ & Polarisability (a.u) & $\beta_{\mathrm{xxy}}$ & 28.668 \\
$\alpha_{\mathrm{yy}}$ & 186.03 & $\beta_{\mathrm{xxz}}$ & 12.4732 \\
$\alpha_{\mathrm{zz}}$ & 185.84 & $\beta_{\mathrm{xzz}}$ & 6.1975 \\
$\alpha_{\mathrm{xy}}$ & 186.77 & $\beta_{\mathrm{yzz}}$ & 1.1069 \\
$\alpha_{\mathrm{xz}}$ & -4.85 & $\beta_{\mathrm{yyz}}$ & -28.1692 \\
$\alpha_{\mathrm{yz}}$ & 1.15 & $\beta_{\mathrm{xyz}}$ & $0.604 \mathrm{x} 10^{-30}$ \\
$\alpha_{\mathrm{o}}(\mathrm{esu})$ & 8.72 & $\beta_{0}(\mathrm{esu})$ & \\
$\Delta \alpha(\mathrm{esu})$ & $2.76 \times 10^{-23}$ & & \\
\hline
\end{tabular}

The calculated hyperpolarizability $(\beta)$ and dipole moment $(\mu)$ of the compound are $0.604 \times 10^{-30}$ esu and $0.92 \mathrm{D}$, respectively [Table 8]. The above result shows that the NLO activity of 3-PDNPO is 2 times that of urea (Jin et al. 1998). The hyperpolarizability values are large for 3-PDNPO compared to Urea. The result also indicates that the magnitude of hyperpolarizability of molecules is dependent upon the availability of the lone pair of electrons on the nitrogen and oxygen atoms.

\section{Conclusions}

In this paper, we have presented a molecular structure and conformational aspects of 3t-pentyl-2r,6c-di(naphthalen-1yl)piperidin-4-one oxime was made by computational analyses and compared with available single crystal XRD data. The data showed that the piperidin-4-one ring adopts chair conformation. The theoretically (B3LYP/6-31G (d,p) constructed IR and Raman spectra are in line with experimentally observed counter parts. The reactive sites within the molecules are understood with the help of Mulliken and MEP surface analyses. The UV-visible spectral results could provide useful information of electronic properties of our compound. The HOMO-LUMO energy gap confirmed the charge transfer taking place within the molecule. The calculated dipole moment and hyperpolarizability results indicate that the significant role in determining the nonlinear optical behaviour.

\section{References}

[1] Klayman, D.L., Bartosevich, J.F., Scott Griffin, T., Mason, C.J., Scovill, J.P., 1979, 2-Acetylpyridine Thiosemicarbazones. A New Class of Poten- 
tial Antimalarial Agents $J$. Med. Chem., 22, 855-862. http://pubs.acs.org/doi/abs/10.1021/jm00193a020.

[2] Gopalakrishnan, M., Sureshkumar, P., Thanusu, J., Kanagarajan, V., 2008, Unusual Formation of N-hydroxy-3,3-dimethyl-2,6diarylpiperidin-4-one and its Thiosemicarbazide Derivative-Synthesis and Antimicrobial Activity, J. Korean Chem. Soc., 52, 503510.https://doi.org/10.5012/jkcs.2008.52.5.503.

[3] Bharti, N., Husain, K., Gonzalez Garza, M.T., Cruz-Vega, D.E., Catro-Garza, J., Mata- Cardenas, B.D., Naqvi, F., Azam, A., 2002, Synthesis and in vitro antiprotozoal activity of 5-nitrothiophene-2carboxaldehyde thiosemicarbazone derivatives, Bioorg. Med. Chem. Lett., 12, 3475-3478.https://doi.org/10.1016/S0960894X(02)00703-5.

[4] Jayabharathi, J., Thanikachalam, V., Padamavathy, M., Srinivasan,N., 2011, Solvatochromic analysis of some $\mathrm{N}$-nitrosooxime derivatives -Taft and Catalan $\begin{array}{llllll}\text { approach, Spectrochim. Acta Part A, } 81 & 380-389 .\end{array}$ https://doi.org/10.1016/j.saa.2011.06.024.

[5] Jayabharathi, J., Thanikachalam,V., Padamavathy, M., Venkatesh Perumal, M., 2012, Photophysical Properties of Novel Picrate Derivatives Solvent Effect, J.Fluoresc., 22 , 269 279. https://doi.org/10.1007/s10895011-0957-5.

[6] Lee, C., Yang, W., Parr, R. G., 1988, Development of the Colle-Salvetti correlation-energy formula into a functional of the electron density, Phys. Rev. B 37, 785 -789. https://doi.org/10.1103/PhysRevB.37.785.

[7] Subashchandrabose, S., Saleem, H., Erdogdu, Y., Rajarajan, G., Thanikachalam, V., 2011, FT-Raman, FT-IR spectra and total energy distribution of 3pentyl-2, 6-diphenylpiperidin-4-one: DFT method, Spectrochimi. Acta Part A, 82, 260-269. https://doi.org/10.1016/j.saa.2011.07.046.

[8] Arockia doss, M., Savithiri, S., Rajarajan, G., Thanikachalam, V., Anbuselvan, C., 2015, Synthesis, electronic structure investigation of 3-pentyl-2,6-di(furan2-yl)piperidin-4-one by FT-IR, FT-Raman and UV-visible spectral studies and ab initio/DFT calculations, Spectrochim. Acta Part A, 151, 773-784. https://doi.org/10.1016/j.saa.2015.07.024.

[9] Anandhy, K., Arockia doss, M., Savithiri, S., Rajarajan, G., Mahalakshmi, S., 2016, Molecular structure, spectroscopic (FT-IR and FT-Raman) of 3-butyl-2,6-di (naphthalen-1-yl) phenylpiperidin-4one: A experimental andDFT study, Int. J. Adv. Res. Trends Eng. Technol., 3(2),1301-1311.

[10] Savithiri, S., Rajarajan, G., Srividhya, V., Jijesh, J., Thanikachalam, V., Jayabharathi, J., Arockia doss, M., 2014, Synthesis, Spectral and Structure Activity Relationship Studies of Substituted 3tpentyl-2r, 6c-diarylpiperidin-4-ones and their Corresponding Oxime Derivatives, Can. Chem. Trans., 2, 201-220 https://doi.org/10.13179/canchemtrans.2014.02.02.0090.

[11] Frisch, M.J., et al., Gaussian 03, Revision E.01, Gaussian Inc, Wallingford, CT,2004.

[12] Arockia doss, M., Savithiri, S., Rajarajan, G., Thanikachalam, V., Saleem, H., 2015, Synthesis, spectroscopic (FT-IR, FT-Raman, UV and NMR) and computational studies on 3t-pentyl-2r, 6cdiphenylpiperidin-4-one semicarbazone, Spectrochim. Acta Part A, 148, 189-202. https://doi.org/10.1016/j.saa.2015.03.117.

[13] Manimekalai, A., Maruthavanan, T., Selvaraju, K., 2012, DFT and experimental prediction of negative chemical shifts of methyl protons in some piperidines, Spectrochim. Acta Part A, 97 942-947. https://doi.org/10.1016/j.saa.2012.07.089.

[14] Arockia doss, M., Rajarajan, G., Thanikachalam, V., Selvanayagam, S., Sridhar, B., 2017, Synthesis, spectroscopic (UV-vis, FT-IR and NMR), single crystal XRD of 3, 5-diethyl -2, 6-di (thiophen-2-yl) piperidin-4-on-1-ium picrate: A comprehensive experimental and computational study, J. Mol. Struct., 1128, 268-278. https://doi.org/10.1016/i.molstruc.2016.08.065.

[15] Gayathri, P., Jayabharathi, J., Rajarajan, G., Thiruvalluvar, A., Butcher, R.J., 2009, t-3-Pentyl-r-2, c-6-diphenyl-piperidin-4-one, Acta Cryst., 65E, o3083. https://doi.org/10.1107/s1600536809046753.

[16] Jayabharathi,J., Thangamani, A., Balamurugan, S., A. Thiruvalluvar, A. Linden, 2008, t-3-Benzyl-r-2,c-6-bis-(4-methoxy-phen-yl)piperidin-4-one oxime, Acta Cryst., 64E, o1211. https://doi.org/10.1107/S1600536808016449.

[17] Socrates, G., 1980, Infrared Characteristic Group Frequencies, third ed., Wiley Interscience Publications, New York.

[18] Pavia, D.L., Lampman, G.M., Kriz, G.S., Vyvyan, J.R., 2008, Spectroscpoy, CengageLearing, New York.

[19] Silverstein, R.M., Webster, F.X., 2005, Spectroscopic Identification of Organic Compounds, $7^{\text {th }}($ Edn), Wiley, New York.

[20] Szafran, M., Komasa, A., Adamska, E.B., 2007, Crystal and molecular structure of 4-carboxypiperidinium chloride (4-piperidinecarboxylic acid hydrochloride), J. Mol. Struct., 827, 101-107. https://doi.org/10.1016/j.molstruc.2006.05.012.

[21] James, C., Amal Raj, A., Reghunathan, R., Hubert Joe, I., Jayakumar, V.S., 2006, Structural conformation and vibrational spectroscopic studies of 2,6-bis(p-
$\mathrm{N}, \mathrm{N}$-dimethyl benzylidene)cyclohexanone using density functional theory, J. Raman Spectrosc., 37, 1381-1392. https://doi.org/10.1002/jis.1554.

[22] Arockia doss, M.,Amala, S., Rajarajan, G., Thanikachalam, V., 2016, Synthesis, Spectral (Uv-Vis, FT-IR and NMR), Molecular structure, NBO, HOMO-LUMO and NLO Analysis of Some 3t-pentyl-2r,6cdiarylpiperidin-4-one Semicarbazones, Can. Chem. Trans., 4, 398-414. DOI:10.13179/canchemtrans.2016.03.0330.

[23] Okulik, N..Jubert, A.H., 2005, Theoretical Analysis of the Reactive Sites of Non-steroidal Anti-inflammatory Drugs, Internet Electron J. Mol. Des., 4, 17-30.

[24] Vijayan, N., Babu, R.R., Gopalakrishnan, R., Dhanuskodi, S., Ramasamy, P. 2002, Growth of semicarbazone of benzophenone single crystals, J. Cryst. Growth, 236, 407-412. https://doi.org/10.1016/S0022-0248(01)02207-2.

[25] Savithiri, S.,Arockia doss, M., Rajarajan, G., Thanikachalam, V., Bharanidharan, S., Saleem, H., 2015, Spectroscopic (FT-IR, FTRaman) and quantum mechanical studies of 3t-pentyl-2r, 6cdiphenylpiperidin-4-one thiosemicarbazone, Spectrochim. Acta Part A, 136, 782-792. https://doi.org/10.1016/j.saa.2014.09.095.

[26] Gorelsky, S.I., 2013, SWizard program, http://www.sg-chem.net/, University of Ottawa, Ottawa, Canada.

[27] Mulliken, R.S., 1995, Electronic Population Analysis on LCAOMO Molecular Wave Functions. J. Chem. Phys. 23, 1833-1840. https://doi.org/10.1063/1.1740588.

[28] Fleming, I., 1976, Frontier Orbitals, Organic Chemical Reactions, Wiley, London.

[29] Curtiss, L.A., Redfern, P.C., Raghavachari, K., Pople, J.A., 1998, Gaussian-3 theory using density functional geometries and zero-point energies, $J$. Chem. Phys., 42, 117-122. https://doi.org/10.1063/1.478676.

[30] Fukui, K., 1982, Role of frontier orbitals in chemical reactions, Science, 218,747-754.https://doi.org/10.1126/science.218.4574.747.

[31] Udhayakala, P., Rajendiran, T., Seshadri, S., Gunasekaran, S., 2011, Quantum chemical vibrational study, molecular property and HOMO-LUMO energies of 3-bromoacetophenone for Pharmaceutical application, J. Chem. Pharm. Res., 3(3) 610-625.

[32] Subramanian, N., Sundaraganesan, N., Jayabharathi, J., 2010, Molecular structure, spectroscopic (FT-IR, FT-Raman, NMR, UV) studies and first-order molecular hyperpolarizabilities of 1,2-bis(3-methoxy-4 hydroxybenzylidene)hydrazine by density functional method, Spectrochim. Acta A, 76, 259-269. https://doi.org/10.1016/j.saa.2010.03.033.

[33] Sun, Y., Chen, X., Sun, L., Guo, X., Lu, W., 2003, Nanoring structure and optical properties of $\mathrm{Ga}_{8} \mathrm{As}_{8}$, Chem. Phys. Lett. 381, 397-403. https://doi.org/10.1016/j.cplett.2003.09.115.

[34] Christiansen, O., Gauss, J., Stanton, J.F., 1999, Frequencydependent polarizabilities and first hyperpolarizabilities of $\mathrm{CO}$ and $\mathrm{H}_{2} \mathrm{O}$ from coupled cluster calculations. Chem. Phys. Lett., 305,147155. https://doi.org/10.1016/S0009-2614(99)00358-9.

[35] Kleinman, D.A., 1977, Nonlinear Dielectric Polarization in Optical Media Phys. Rev. 126, 1962. https://doi.org/10.1103/PhysRev.126.1977.

[36] Labidia, N.S., Djebaili, A., 2010, Enhancement of molecular polarizabilities by the push-pull mechanism: A DFT study of substituted hexatriene, Mater. Sci. Eng. B169 8-12. https://doi.org/10.1016/j.mseb.2009.12.043.

[37] Vijayakumar, T., Hubert Joe, I., Reghunadhan Nair, C.P., Jayakumar, V.S., 2008, Efficient $\pi$ electrons delocalization in prospective push-pul non-linear optical chromophore 4-[N, N-dimethylamino]-4'-nitro stilbene (DANS): A vibrational spectroscopic study, Chem. Phys., 34383 99. https://doi.org/10.1016/j.chemphys.2007.10.033.

[38] Jin, Z- M.,Zhou, W.Jin, Z., 1988, X-ray powder diffraction analysis of a nonlinear optical material 1-benzoyl-3-(4-benzyl)thiourea [Nbenzoyl-N'-(4-benzyl)thiourea] Powder diff., 13, 41-43. 